\title{
ON NECROSIS OF THE FEMORAL HEAD AFTER FRACTURE OF THE NECK OF THE FEMUR
}

\author{
A Microradiographic and Histological Study
}

\author{
H. Bohr and E. Hualmar Larsen, Copenhagen, Denmark
}

From the Orthopaedic Hospital, Copenhagen

It is usually considered a sign of necrosis of the femoral head when increased density of the head is observed radiologically after a fracture of the neck of the femur or traumatic dislocation of the hip joint. This conclusion probably arises from comparison with the sclerosis observed in radiographs of bone sequestra, although various suggestions have been made about the cause of this sclerosis. Thus Phemister (1920) claimed that the increased density of bone sequestra was only apparent and caused by decalcification of the surrounding bone. $\mathrm{He}$ described the demarcation zone and the erosion on the surface of the sequestrum as signs of ingrowth of granulation tissue and revascularisation, and introduced the term "creeping substitution." In their work on bone grafting in cases of non-union of fractures of the femoral neck Bonfiglio and Bardenstein (1958) showed that in the last stages of repair in sclerosis of the femoral head deposition of new bone upon the necrotic trabeculae could be demonstrated. This observation was confirmed in experiments on rabbits by Bobechko and Harris (1960) who showed that the increased density after devascularisation of the femoral head was produced by apposition of new bone on the devitalised structures. They introduced the term " creeping apposition "for this process. Hulth (1961) showed that the sclerotic areas in femoral heads removed eighteen months to four years after fracture of the femoral neck consisted of revitalised bone with broader trabeculae and irregular mineralisation.

In the present study histological and microradiographic investigations have been carried out on femoral heads after fracture of the femoral neck in order to follow more closely the processes leading to sclerosis.

\section{MATERIAL AND METHODS}

From the patients treated at the Orthopaedic Hospital by arthroplasty of the hip for fracture of the femoral neck, twenty operated upon from five days to five years after injury were selected for further study. In seven cases the femoral head was removed within one month of the fracture (Group 1), in six there was an interval of from one month to one year (Group 2) and in seven there was an interval of from one to five years (Group 3) (Table I). The appearance of the femoral head in radiographs was classed as normal, sclerotic or osteoporotic, in comparison with the head of the intact femur.

Estimation of degree of mineralisation-The femoral head was sectioned longitudinally and a sample one centimetre thick was embedded in methylmethacrylate, cut and ground to approximately 70 microns thickness. Contact microradiography was performed with soft $\mathrm{x}$-rays generated at a maximum of 12 kilovolts and 20 milliamperes from a Machlett A.E.G. $50 \mathrm{x}$-ray tube, with a tungsten anode of 2-millimetre focus size. The focus-film distance was 16 centimetres and the exposure time was ten minutes. The width of the trabecular structure was classed as normal, broad or thin.

In order to estimate the degree of mineralisation of the bone a reference frame consisting of aluminium foils 1 millimetre, $\cdot 5$ millimetre and $\cdot 3$ millimetre thick was superimposed on each film, and the absorption of the x-rays was determined by densitometry within areas of .3 square millimetre of trabecular bone. The thickness of the bone in the areas measured was determined by point micrometry. For each exposure a graph of the density of the aluminium foils in relation to their thickness was made as a reference code, and the degree of mineralisation of the bone tissue was expressed in microns of aluminium corresponding to bone 100 microns thick. 
Histological examinations of neighbouring sections of the head were made after decalcification and staining with haematoxylin and eosin. The results were expressed in terms of viability of bone. Survival of original bone was classed as total, partial or none, according to the comparative numbers of living osteocytes and of empty lacunae. The amount of apposition of new bone was also recorded.

In several cases a tetracycline was given orally, as Ledermycin 300 milligrams three times a day for two days, starting forty-eight hours before the removal of the femoral head, and the sections were examined for fluorescence by exposure to ultraviolet light.

\section{RESULTS}

Radiological appearance-The appearance of the head was normal in all cases examined within a month of injury; of those examined at intervals of from one month to one year after injury

TABLE I

Clinical Material. Results of Radiography, Microradiography and Histological Examination

\begin{tabular}{|c|c|c|c|c|c|c|c|c|c|}
\hline \multirow[b]{2}{*}{$\begin{array}{c}\text { Case } \\
\text { number }\end{array}$} & \multirow[b]{2}{*}{ Sex } & \multirow[b]{2}{*}{$\begin{array}{c}\text { Age } \\
(\text { years })\end{array}$} & \multirow{2}{*}{\begin{tabular}{|c|} 
Interval \\
between \\
fracture \\
and \\
operation
\end{tabular}} & \multirow[b]{2}{*}{ Radiograph } & \multicolumn{2}{|c|}{ Microradiography } & \multicolumn{2}{|c|}{$\begin{array}{c}\text { Histological } \\
\text { examination }\end{array}$} & \multirow{2}{*}{$\begin{array}{c}\text { Uptake } \\
\text { of } \\
\text { tetracycline }\end{array}$} \\
\hline & & & & & $\begin{array}{c}\text { Width } \\
\text { of } \\
\text { trabeculae }\end{array}$ & $\begin{array}{c}\text { Mineral- } \\
\text { isation } \\
\text { in microns } \\
\text { of aluminium }\end{array}$ & $\begin{array}{c}\text { Survival } \\
\text { of } \\
\text { trabeculae }\end{array}$ & $\begin{array}{c}\text { Apposition } \\
\text { of } \\
\text { new bone }\end{array}$ & \\
\hline 1 & $F$ & 79 & 5 days & Normal & Normal & 74 & Partial & 0 & 0 \\
\hline 2 & $F$ & 90 & 7 days & Normal & Normal & 85 & Partial & 0 & \\
\hline 3 & $F$ & 81 & 10 days & Normal & Normal & 79 & Partial & 0 & 0 \\
\hline 4 & F & 84 & 12 days & Normal & Normal & 78 & None & 0 & 0 \\
\hline 5 & $\mathbf{M}$ & 71 & 18 days & Normal & Normal & 80 & None & 0 & 0 \\
\hline 6 & $F$ & 85 & 21 days & Normal & Normal & 83 & Partial & 0 & \\
\hline 7 & $M$ & 65 & 29 days & Normal & Normal & 75 & Partial & 0 & \\
\hline 8 & F & 72 & 3 months & Normal & Normal & 73 & None & 0 & \\
\hline 9 & $F$ & 65 & $3 \frac{1}{2}$ months & Normal & Normal & 78 & Partial & 0 & \\
\hline 10 & $F$ & 70 & $8 \frac{1}{2}$ months & Sclerosis & Broad & 75 & None & . & \\
\hline 11 & $\mathbf{M}$ & 60 & 9 months & Osteoporosis & Thin & 79 & Total & 0 & + \\
\hline 12 & F & 70 & 111 months & Normal & Normal & 78 & Total & 0 & \\
\hline 13 & $F$ & 60 & 12 months & Sclerosis & Broad & 77 & None & $\div$ & \\
\hline 14 & F & 70 & 13 months & Normal & Normal & 71 & None & 0 & \\
\hline 15 & $F$ & 58 & 13 months & Sclerosis & Broad & 69 & None & $\therefore$ & \\
\hline 16 & $\bar{F}$ & 89 & 11 years & Sclerosis & Broad & 78 & Partial & $\therefore$ & \\
\hline 17 & $F$ & 63 & 2 years & Normal & Normal & 84 & None & 0 & \\
\hline 18 & $F$ & 84 & 21 years & Sclerosis & Broad & 78 & None & $!$ & 4 \\
\hline 19 & $F$ & 63 & 3 years & Sclerosis & Broad & 63 & None & + & + \\
\hline 20 & $F$ & 63 & 5 years & Sclerosis & Broad & 75 & None & $i$ & + \\
\hline
\end{tabular}

VOL. 47 B, NO. 2, MAY 1965 
two were classed as sclerotic; all but two of those examined more than a year after injury showed partial or total sclerosis (Table I).

Degree of mineralisation-In Group 1 the density varied from 85 to 74 microns of aluminium, with an average of $79 \pm 3$ microns. This represents the density of cancellous bone in the normal femoral head, since no significant change could have occurred in the inorganic tissue within a month of injury. In the other groups the density varied from 84 to 63 microns of aluminium, with an average of $75 \pm 7$ microns, which does not differ significantly from the findings in the first group. Furthermore, there was no difference between the heads showing and those not showing sclerosis. On the other hand, there was a direct correlation between the radiological assessment of sclerosis and the width of the trabecular structures.

Histological results - In all heads of Group 1 empty lacunae were present in the central part of the trabeculae and correspondingly no uptake of tetracycline could be demonstrated in the four cases tested. The results in the other groups are given in the next section.

\section{PROGRESSION OF CHANGES IN THE FEMORAL HEAD}

Changes at three weeks-A woman of eighty-five (Case 6) sustained a fracture of the femoral neck. Three weeks later replacement arthroplasty was done. At that stage radiographs showed no significant difference between the heads of the injured and uninjured femora (Figs. 1 and 2). Microradiography gave results inside the normal range (Figs. 3 and 4). Histological examination showed that the central part of the trabeculae was necrotic, whereas living osteocytes and osteoblasts remained on the surface (Figs. 5 and 6).

Changes at eight months-A woman of eighty-one (Case 10) sustained a fracture of the femoral neck from a fall. Replacement arthroplasty was done eight months later. Radiographs showed distinct sclerosis of the femoral head (Figs. 7 and 8). The microradiographic investigation showed the mineralisation of the bone to be within normal limits, but the trabeculae were broader than normal (Figs. 9 and 10). The histological examination showed that this was produced by the deposition of new bone upon dead trabeculae (Figs. 11 and 12).

Changes at nine months - A man of sixty (Case 11) sustained a fracture of the femoral neck from a fall. Nine months later replacement arthroplasty was done. Radiographs showed osteoporosis of the femoral head (Figs. 13 and 14). The microradiographic investigation showed very thin trabeculae with a normal degree of mineralisation (Figs. 15 and 16). Histological examination showed the bone had survived practically everywhere: there were living osteocytes in all the lacunae, but relatively few osteoblasts on the surfaces of the trabeculae (Figs. 17 and 18). A distinct uptake of tetracycline was observed.

Changes at two years-A woman of sixty-three (Case 17) sustained a fracture of the femoral neck from a fall. Despite fixation with a Smith-Petersen pin the fracture did not heal. Two years later replacement arthroplasty was done. The density of the head seemed to be increased, but this was only apparent, being caused by the osteoporosis of the surrounding bone, as shown by comparison with the intact femur (Figs. 19 and 20). Microradiography showed normal mineralisation and width of the trabecular structures (Figs. 21 and 22). Histological examination showed that all the bone was necrotic: there were no surviving osteocytes and no apposition of new bone (Figs. 23 and 24).

Changes at five years-A woman of sixty-three (Case 20) sustained a fracture of the femoral neck from a fall. Replacement arthroplasty was done five years later. Radiographs showed total sclerosis and some deformity of the femoral head (Figs. 25 and 26). The microradiographic examination showed that the mineralisation was normal, but that the trabeculae were very broad (Figs. 27 and 28). Histological examination showed apposition of living bone corresponding to the increased width of the trabeculae. Most of the necrotic bone had been resorbed (Figs. 29 and 30). A marked uptake of tetracycline was seen. 


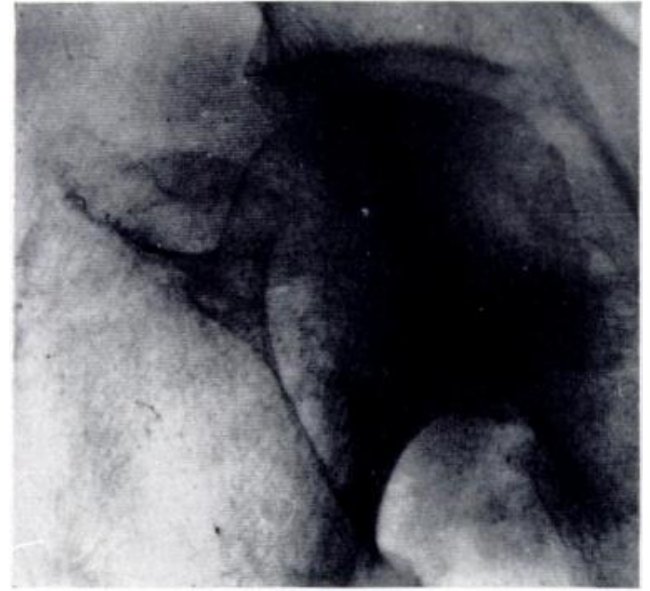

FIG. 1

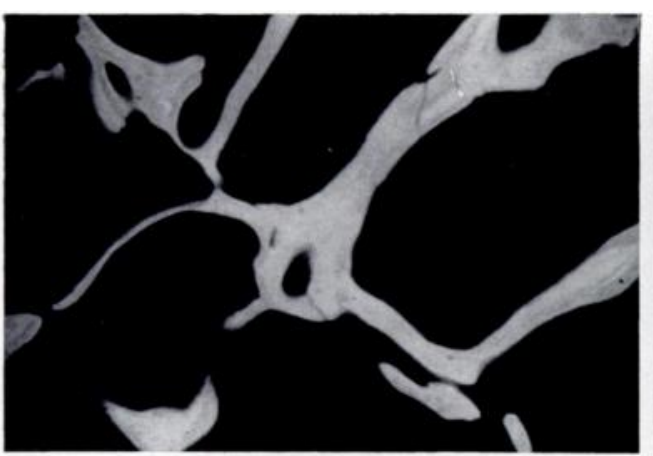

Fig. 3

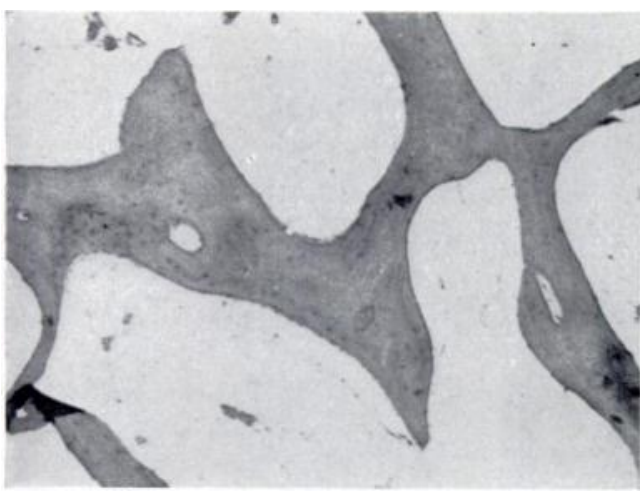

Fig. 5

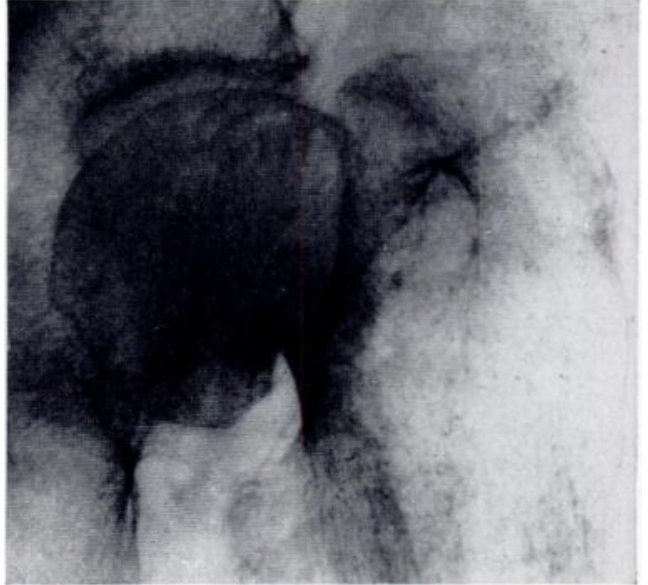

FiG. 2

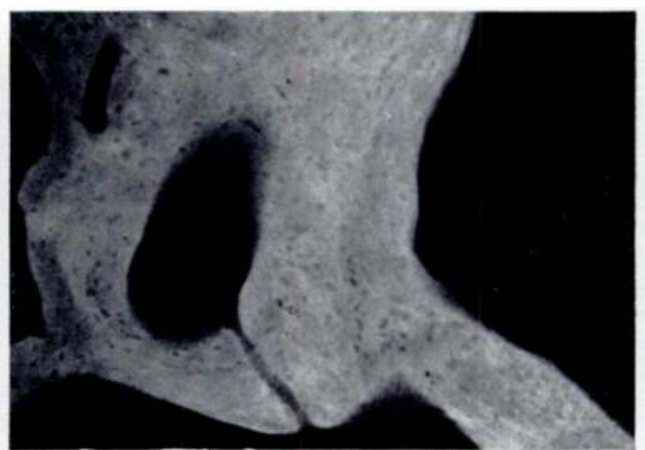

FIG. 4

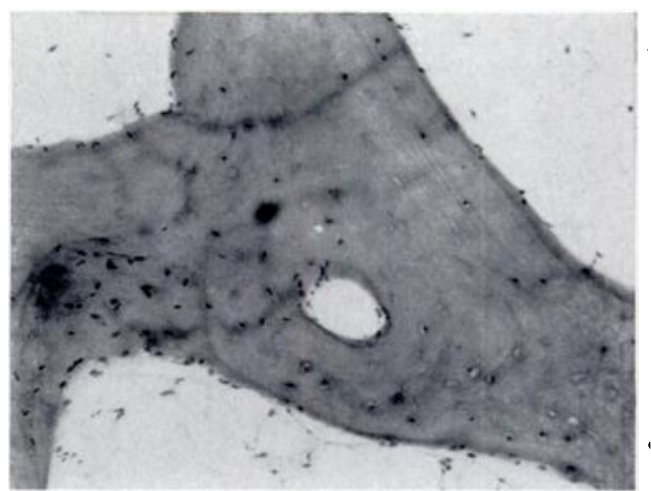

FIG. 6

Case 6-Appearances three weeks after fracture. Figures 1 and 2-Radiographs showing normal density of the femoral head. Figures 3 and 4-Microradiographs showing normal width of trabeculae. (Figure 3-magnification, 6; Figure 4-magnification, $\times 25$.) Figures 5 and 6-Histological sections showing central necrosis of the trabeculae. (Haematoxylin and eosin.) (Figure 5-magnification, $\times 10$; Figure 6-magnification, 25.) 


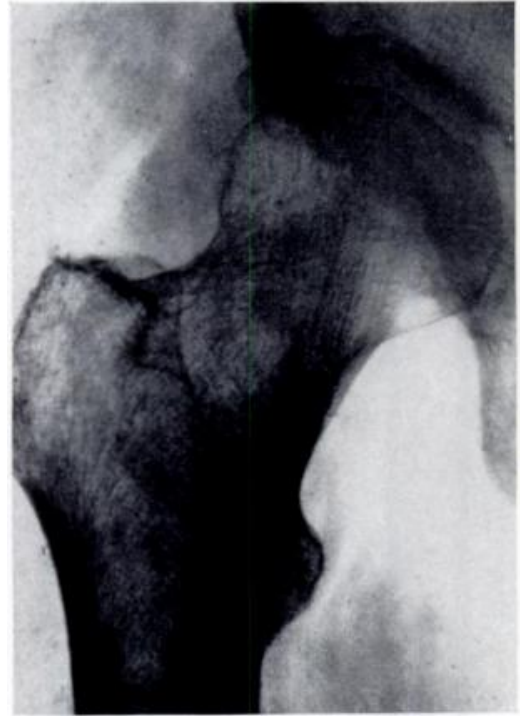

Fig. 7

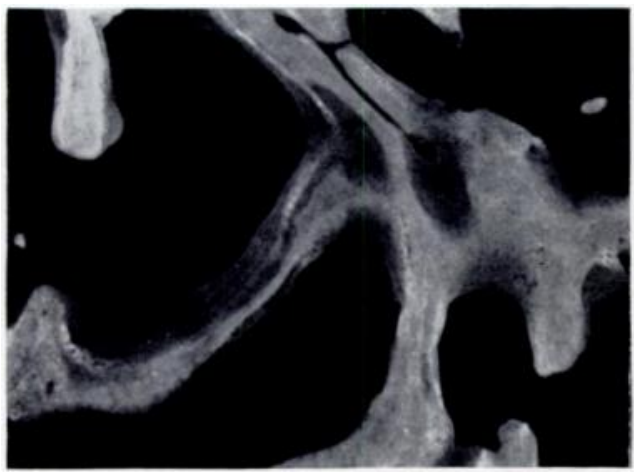

FIG. 9

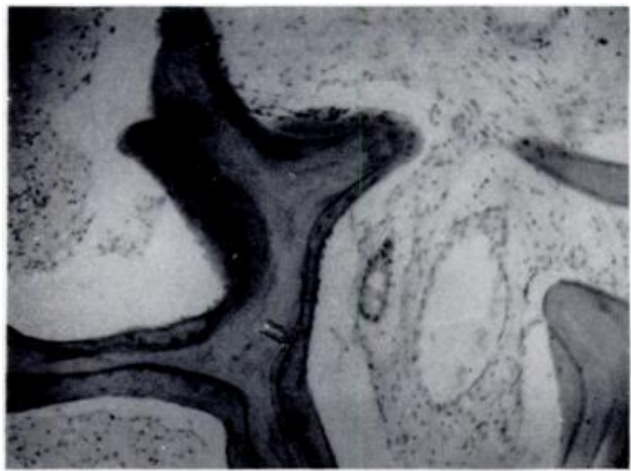

Fig. 11

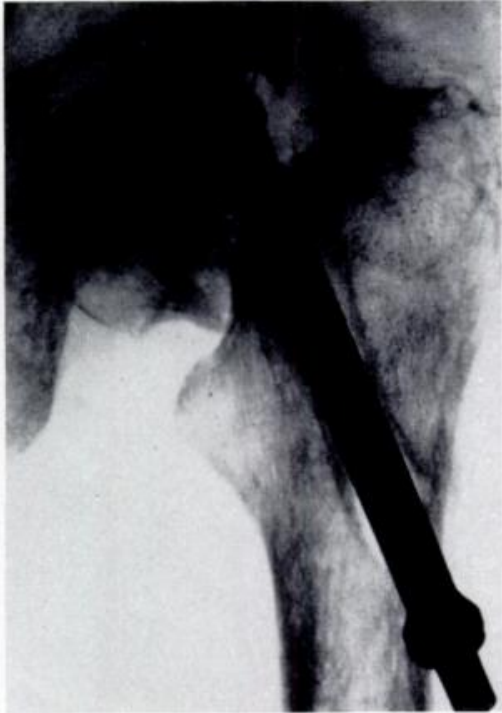

FiG. 8

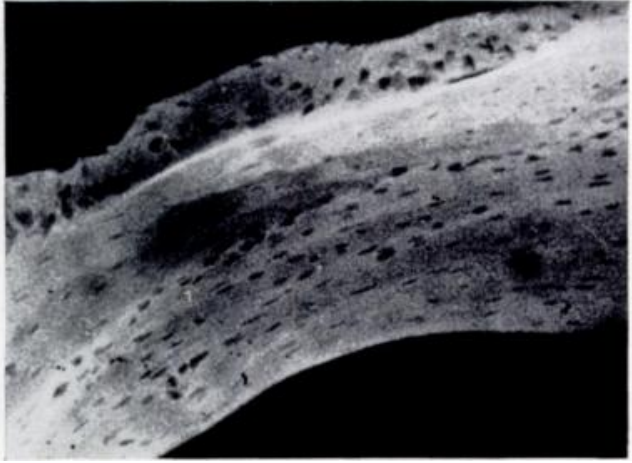

FIG. 10

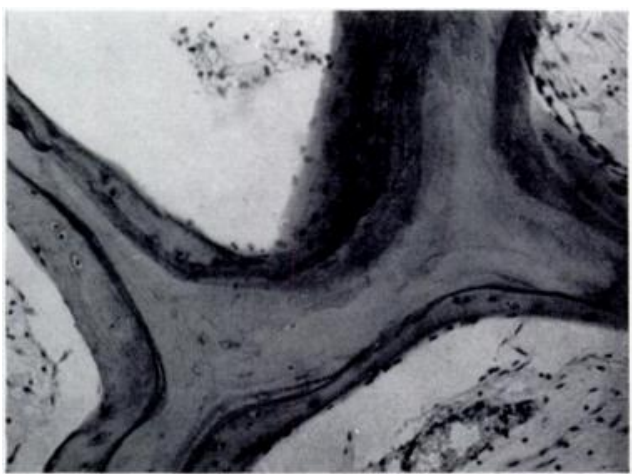

Fig. 12

Case 10-Appearances eight months after fracture. Figures 7 and 8-Radiographs showing sclerosis of the femoral head. Figures 9 and 10-Microradiographs showing trabeculae broader than normal. (Figure 9-magnification, 6; Figure 10-magnification. 25.) Figures 11 and 12-Histological sections showing apposition of new bone on necrotic trabeculae. (Figure 11-magnification, 10: Figure 12-magnification, 25.) 


\section{DISCUSSION AND CONCLLSIONS}

It is well known that the density of the bone seen in the ordinary radiograph is dependent on the total amount of bone which the x-rays have to penetrate, as well as on the degree of mineralisation of the bone. It has been shown by microradiographic investigations (Amprino

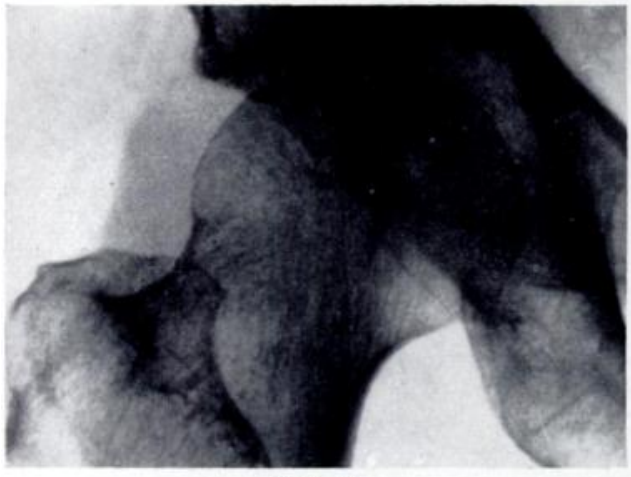

FIG. 13

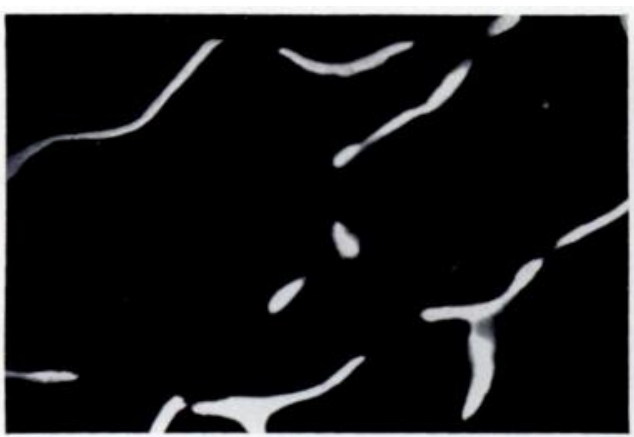

FIG. 15

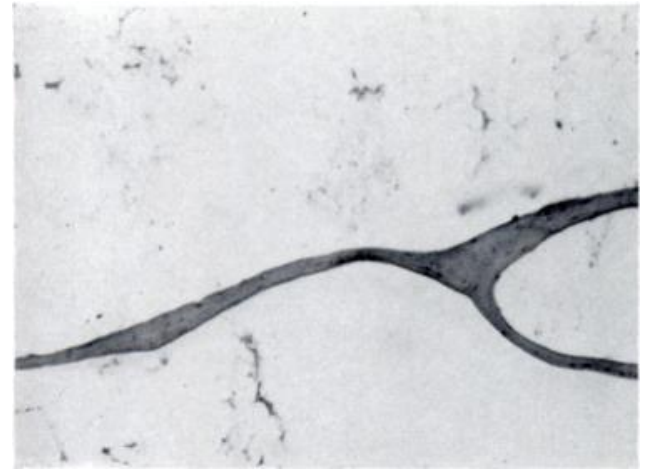

Fig. 17

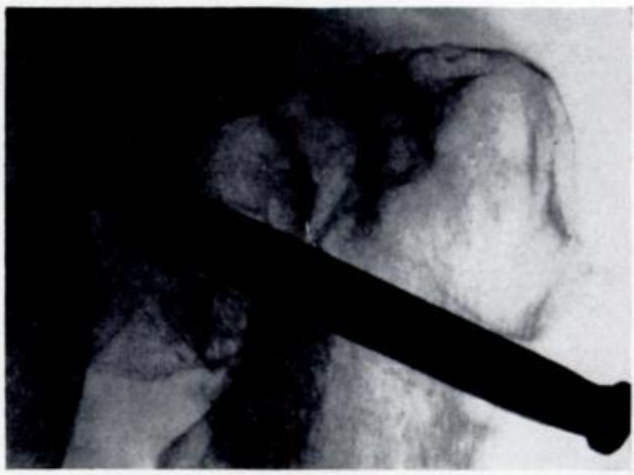

FIG. 14

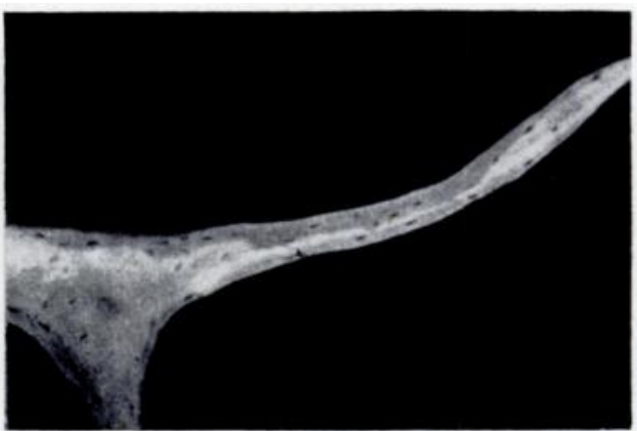

FIG. 16

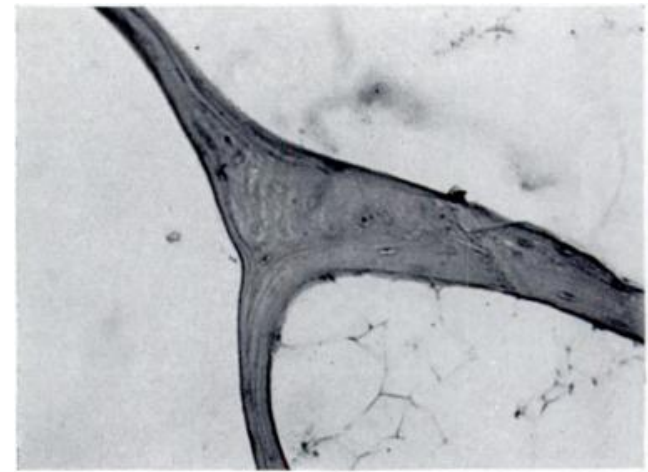

FIG. 18

Case 11-Appearances nine months after fracture. Figures 13 and 14-Radiographs showing osteoporosis of the femoral head. Figures 15 and 16-Microradiographs showing trabeculae thinner than normal. (Figure 15-magnification, 6; Figure 16-magnification, $\times 25$.) Figures 17 and $18-$ Histological sections showing living bone, but only few osteoblasts. (Figure 17-magnification, $\times 10$ : Figure 18-magnification, $\times 25$.)

and Engström 1952) that the mineralisation in normal living bone varies, and quantitative determinations have shown a difference of 20 to 30 per cent between the lowest and highest mineralisation in compact bone (Engström, Bellman and Engfeldt 1955; Strandh 1960). From

VOL. 47 B, NO. 2, MAY 1965 


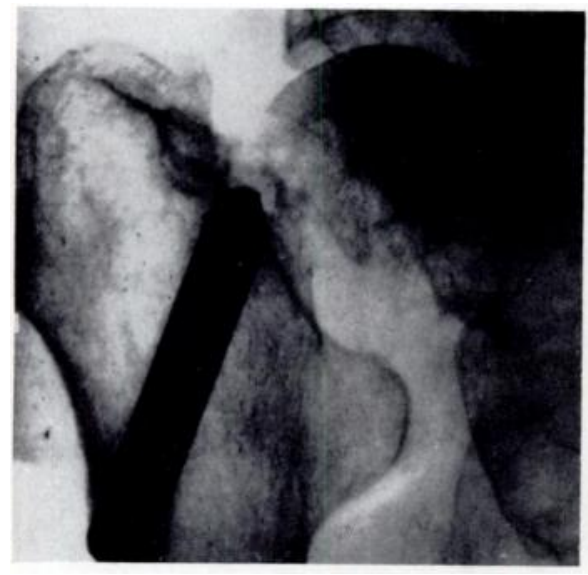

FiG. 19

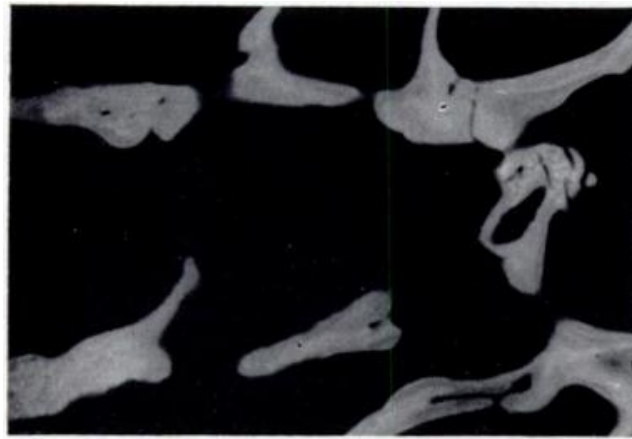

Fig. 21

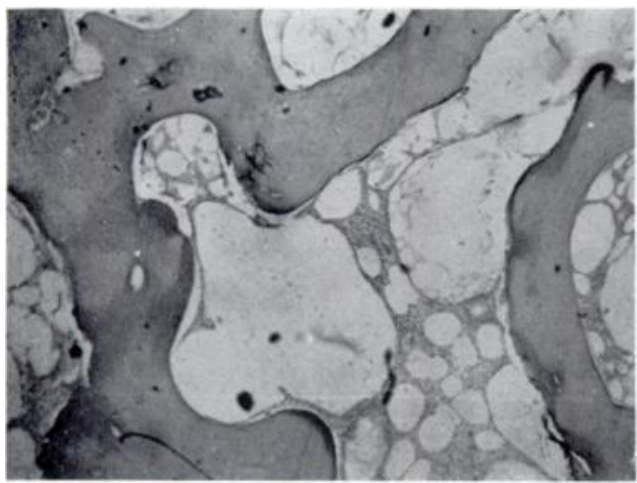

FIG. 23

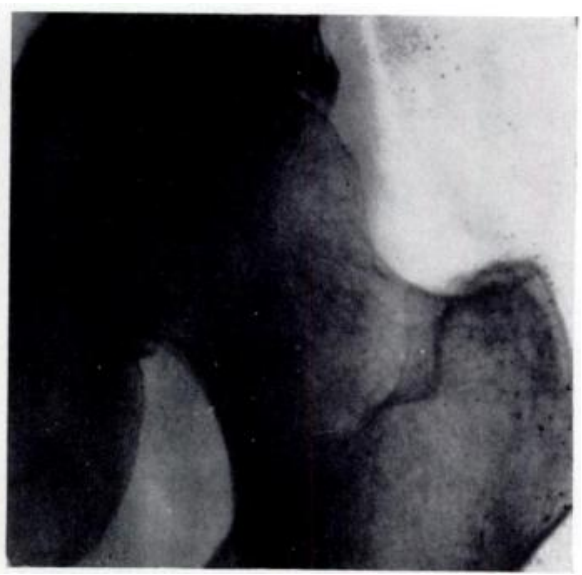

FIG. 20

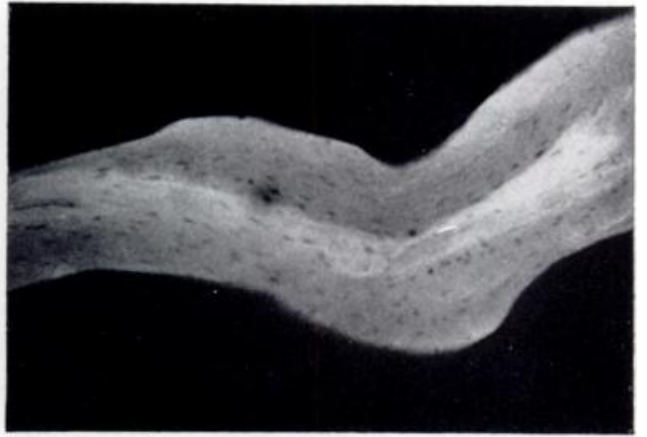

FIG. 22

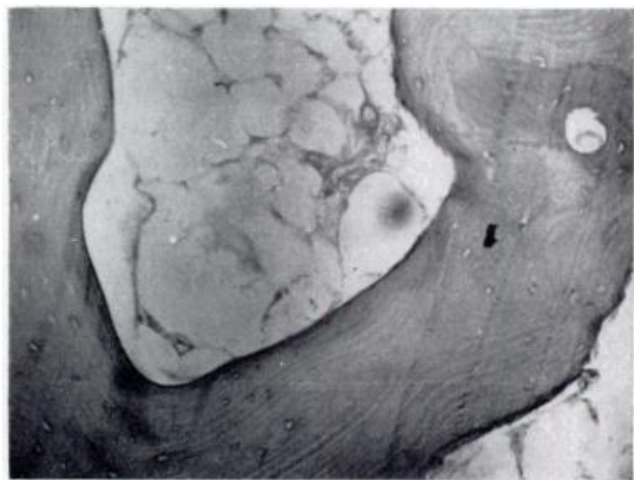

FIG. 24

Case 17-Appearances two years after fracture. Figures 19 and 20-Radiographs showing relative sclerosis of the femoral head, contrasting with osteoporosis of the surrounding bone. Figures 21 and 22-Microradiographs showing normal width of trabeculae. (Figure 21-magnification, $\times 6$; Figure 22magnification, $\times 25$.) Figures 23 and 24 - Histological sections showing necrotic trabeculae. (Figure $23-$ magnification, $\times 10$; Figure $24-$ magnification, $\times 25$.)

the present study it appears that the average mineralisation of the cancellous bone in the femoral head after fracture of the neck of the femur is the same whether the head is sclerotic, osteoporotic or normal. Furthermore, the variation in mineralisation of the necrotic bone is the same as in the living bone. The increased density observed in the radiograph must therefore be due to an increased amount of bone per unit volume. In support of these views it has been 


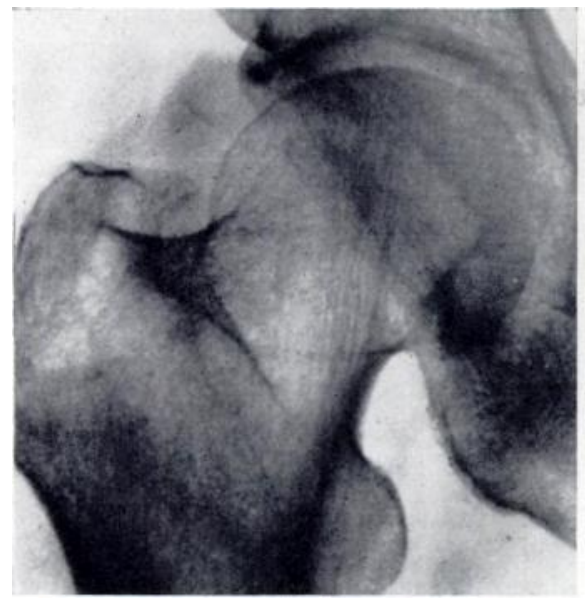

FiG. 25

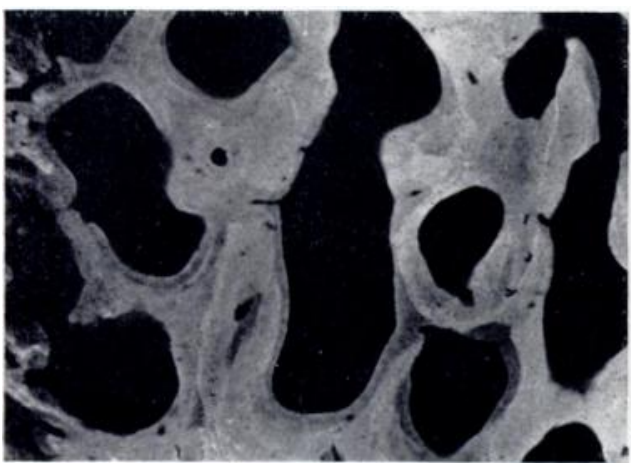

FIG. 27

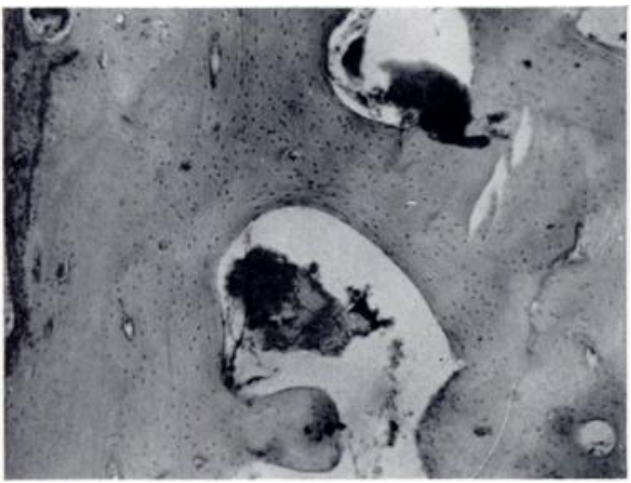

Fig. 29

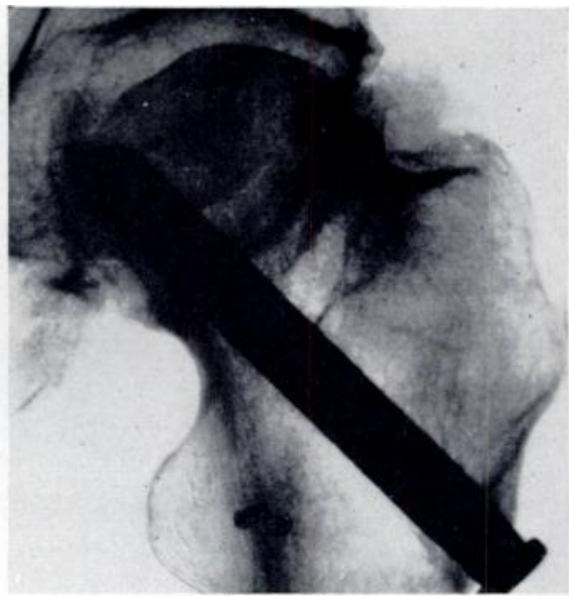

FIG. 26

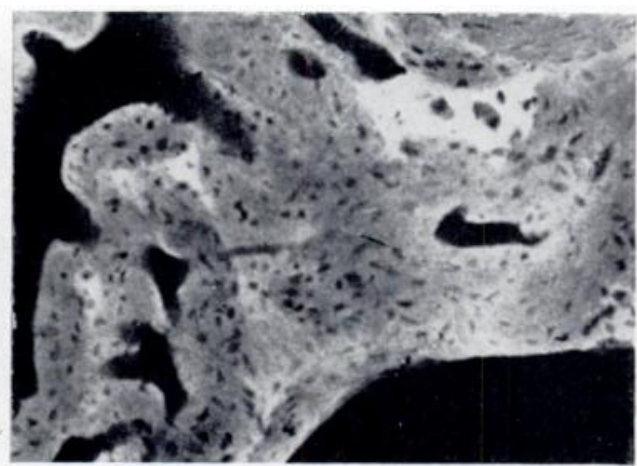

FIG. 28

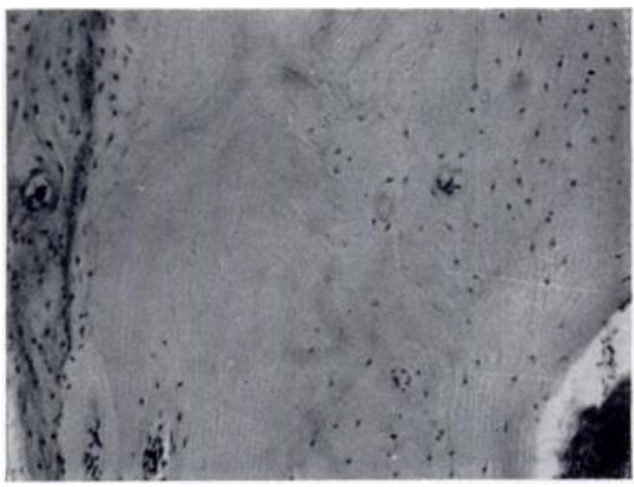

Fig. 30

Case 20-Appearances five years after fracture. Figures 25 and 26-Radiographs showing absolute sclerosis of the femoral head. Figures 27 and 28-Microradiographs showing trabeculae broader than normal. (Figure 27-magnification, $\times 6$; Figure 28-magnification, $\times 25$.) Figures 29 and $30-$ Histological sections showing sequestra of necrotic trabeculae surrounded by thick layers of newly formed bone. (Figure 29-magnification, $\times 10$; Figure 30-mangification, $\times 25$.)

shown that in every case in which sclerosis of the femoral head was present increased width of the trabeculae from apposition of new bone could be demonstrated. Thus, although sclerosis of the femoral head after fracture of the femoral neck is a result of necrosis, it is at the same time a definite sign that restitution processes are going on. 
The sequence of events after a fracture of the neck of the femur seems to be as follows: The limited vascular supply of the head of the femur is cut off, so that there is necrosis of the original bone. In the first instance this does not interfere with the inorganic structure of the bone. The further course depends upon the possibility of revascularisation. If the vascular supply has been only temporarily reduced the osteocytes may survive, and following a secondary hyperaemia osteoporosis may develop. If the vascular supply is insufficient and the osteocytes succumb, revascularisation may still eventually take place from the surrounding bone, and granulation tissue will appear, giving rise to creeping apposition on the surfaces of the necrotic trabeculae. Eventually most of the necrotic bone is replaced by new bone, which grows in the broad and irregular trabeculae of the deformed head by creeping substitution. If revascularisation does not take place-for instance, if contact with the femoral neck has not been established or if non-union occurs-the femoral head, though necrotic, may remain undisturbed for at least as long as two years. It must be assumed, however, that the mechanical strength is reduced and that collapse will ultimately occur.

\section{SUMMARY}

1. The development of sclerosis of the femoral head after fracture of the femoral neck has been investigated by a combined microradiographic and histological examination of twenty femoral heads removed during arthroplasty of the hip done at varying intervals after fracture. 2. Mineralisation of the bone did not differ from the normal.

3. There was a direct correlation between the density of the femoral head as judged radiologically and the width of the trabeculae. In cases of sclerosis of the femoral head the trabeculae were broader than normal and histological examination showed that this was caused by apposition of new bone upon the necrotic trabeculae.

4. Although sclerosis is a result of necrosis, it is at the same time a definite sign that revascularisation and restitution are going on.

\section{REFERENCES}

Amprino, R., and Engström, A. (1952): Studies on X Ray Absorption and Diffraction of Bone Tissue. Acta Anatomica, 15, 1.

Bobechko, W. P., and Harris, W. R. (1960): The Radiographic Density of Avascular Bone. Journal of Bone and Joint Surgery, 42-B, 626.

Bonfiglio, M., and Bardenstein, M. B. (1958): Treatment by Bone-Grafting of Aseptic Necrosis of the Femoral Head and Non-Union of the Femoral Neck. (Phemister Technique.) Journal of Bone and Joint Surgery, 40-A, 1329.

Engström, A., Bellman, S., and Engfeldt, B. (1955): Microradiography. British Journal of Radiology, 8, 517. Hulth, A. (1961): Necrosis of the Head of the Femur. Acta Chirurgica Scandinavica, 122, 75.

Phemister, D. B. (1920): The Recognition of Dead Bone Based on Pathological and X-ray Studies. Annals of Surgery, 72, 466.

StrandH, J. (1960): Microchemical Studies on Single Haversian Systems. Experimental Cell Research, $19,515$. 